\title{
O DOMICÍLIO COMO ESPAÇO EDUCATIVO PARA O AUTOCUIDADO DE PUÉRPERAS: BINÔMIO MÃE-FILHO ${ }^{1}$ THE HOME AS EDUCATIONAL SPACE FOR SELF CARE OF PUERPERAS: MOTHER-CHILD BINOMIAL EL DOMICILIO COMO ESPACIO EDUCATIVO PARA EL AUTO-CUIDADO DE PUÉRPERAS: BINOMIO MADRE-HIJO
}

\author{
Dafne Paiva Rodrigues², Ana Fátima Carvalho Fernandes³, Raimunda Magalhães da Silva', Maria Socorro Pereira \\ Rodrigues $^{5}$
}

\begin{abstract}
'Artigo extraído da tese "Representações sociais de puérperas sobre o cuidado de enfermagem recebido no ciclo gravídico-puerperal", defendida em fevereiro de 2005, no Programa de Pós-Graduação em Enfermagem da Universidade Federal do Ceará (UFC).

${ }^{2}$ Doutora em Enfermagem. Professora Adjunto do Curso de Enfermagem da Universidade Estadual do Ceará (UECE). Vice-líder do Grupo de Pesquisa Saúde da Mulher e Família na UECE.

${ }^{3}$ Doutora em Enfermagem. Professora Adjunto do Curso de Enfermagem da UFC. Coordenadora do Programa de Pós-Graduação em Enfermagem da UFC. Coordenadora do Projeto de Pesquisa Saúde da Mulher na UFC.

${ }^{4}$ Doutora em Enfermagem. Coordenadora do Curso de Mestrado em Educação em Saúde da Universidade de Fortaleza (UNIFOR). Coordenadora do Grupo de Pesquisa Saúde da Mulher na UNIFOR.

${ }^{5}$ Doutora em Enfermagem. Professora Adjunto do Programa de Pós-Graduação em Enfermagem da UFC.
\end{abstract}

PALAVRAS-CHAVE: Empatia. Educação. Puerpério.

KEYWORDS: Empathy. Education. Puerperium.

PALABRAS CLAVE: Empatía. Educación. Puerperio.

RESUMO: Analisa as representações sociais de puérperas sobre o cuidado de enfermagem e os ensinamentos recebidos, durante o ciclo puerperal, acerca do autocuidado e do cuidado com seu filho. Realizado em um hospital público de Fortaleza - Ceará e nos domicílios de sete puérperas. O cuidado foi representado com insatisfação pelas puérperas, as quais reportaram-se às orientações recebidas durante a gestação para os cuidados no puerpério, representando-o como um lugar de abandono e que necessita de uma ênfase maior nas orientações e na atenção dispensada à mulher. Por outro lado, a prática educativa possibilitada pelas visitas domiciliares às puérperas foi revelada pelas mesmas como um suporte importante e que deve ser implementada nas instituições de saúde de maneira mais efetiva. Consideramos que a puérpera apresenta uma deficiência de informações sobre o cuidado de si e de seu filho e que necessita de uma rede de apoio para torná-la apta ao desempenho satisfatório da maternidade.

ABSTRACT: This study analyzes the social representations of mothers with newborns on the received teachings, during the pregnant-birth cycle, concerning self care and of care with her newborn. It was carried out at a public hospital of Fortaleza, Ceará, Brazil, and in the homes of seven mothers with newborns. The care was represented with dissatisfaction by the mothers of newborns, who associated it to the orientations received during the gestation for care in the hospital; representing it as a place of abandonment that needs a larger emphasis on the orientations and in the attention given to the woman. On the other hand, the educational practice made possible by the house calls given the mothers of newborns was highlighted by these women as an important function of support. They suggested an integration of this practice in the health care institutions for a more effective support structure. We considered that the mothers of newborns present a deficiency of information on self care and that of her newborn. An adequate support net is necessary in order to make her capable of a satisfactory initial maternity experience.

RESUMEN: Analiza las representaciones sociales de puérperas sobre el cuidado de enfermería y las enseñanzas recibidas durante el ciclo puerperal, sobre el auto-cuidado y el cuidado con su hijo. Realizado en un hospital público de Fortaleza - Ceará y en los domicilios de siete puérperas. El cuidado fue representado con insatisfacción por las puérperas, que se refirieron a las orientaciones recibidas durante la gestación para los cuidados en el puerperio, representándolo como un lugar de abandono y que necesita un mayor énfasis en las orientaciones y en la atención dispensada a la mujer. Por otro lado, la práctica educativa posibilitada por las visitas domiciliares a las puérperas fue revelada por las mismas como un apoyo importante que debe ser implementado en las instituciones de salud de forma más efectiva. Consideramos que la puérpera presenta un déficit de información sobre el cuidado de sí y de su hijo y que necesita una red de apoyo para dejarla apta para el desempeño satisfactorio de la maternidad.

Endereço: Dafne Paiva Rodrigues R. Francisco Glicério, 937, Bl. A, Ap. 103 60.711-050 - Maraponga, Fortaleza, CE. E-mail: dafneprodrigues@yahoo.com.br
Artigo original: Pesquisa Recebido em: 22 de novembro de 2005. Aprovação final: 02 de maio de 2006. 


\section{INTRODUÇÃO}

O cuidado enquanto essência da assistência da enfermagem vem, há tempos, tendo sua prática incorporada à saúde da mulher, no ciclo gravídico-puerperal, apesar das diversas conotações, que variam desde a abordagem puramente tecnicista até aquela que envolve uma prática individualizada e humanizada, centrada na totalidade do ser humano, a partir de suas necessidades biofisiológicas e psicossociais. Essa abordagem, que tem em vista a promoção do bem-estar e a prevenção de complicações, e que neste trabalho focaliza mulheres, refere-se ao âmbito obstétrico e contempla o acompanhamento diário através do exame físico, privilegiando os aspectos psicológicos e espirituais e o respeito às crenças religiosas e seu significado para a saúde dessa mulher, visto que no puerpério a atenção, o carinho e outros cuidados especiais poderão ser fundamentais, por auxiliarem na superação de dificuldades e encorajarem a verbalização de dúvidas e ansiedades. Há de se incluir, necessariamente, questões sociológicas, por possibilitarem à mulher liberdade na interação com seu filho, seus familiares e outros entes significativos para ela. Dessa forma, poder-se-á estar cooperando para que a mulher goze de plena saúde e vivencie de forma plena e feliz o processo de cuidados, durante seu gestar, parir e reintegrar-se ao seu fazer cotidiano.

Percebemos na comunicação, enquanto forma de interação enfermeiro-cliente, um aspecto relevante na prática da humanização do cuidado de enfermagem, em particular no que se refere ao cuidar da mulher em sua totalidade, de forma personalizada. $\mathrm{Na}$ instância da assistência de enfermagem é necessário levar em conta sentimentos e experiências, relacionados à gravidez e à parturição, de forma que o parto lhe seja apresentado como um acontecimento simples, natural, agradável, benévolo e verdadeiramente benigno. $\mathrm{O}$ ouvir atentamente sem julgamentos, o necessário respeito às várias necessidades particularizando a empatia, tolerância, disponibilidade, comparecimento, autenticidade, confiança, diálogo, preservação da individualidade do outro e troca de experiências fazem-se necessários, a fim de que o cuidado possa transcender a biologia e abranger aspectos das várias dimensões do ser. ${ }^{1-3}$

Uma boa orientação, devidamente contextualizada ao cuidado e embasada em uma relação de confiança entre enfermeiro-parturiente, poderá repercutir não só na qualidade dos sentimentos manifestos pela mulher, mas também culminar em uma adaptação saudável da puérpera ao seu papel materno. ${ }^{4}$

O presente estudo visa analisar, a partir da representação da mulher, as orientações recebidas por ocasião do cuidado de enfermagem no pós-parto, de forma a oferecer subsídios para uma adequada definição da assistência de enfermagem em moldes humanizados, no âmbito da prática obstétrica, particularizando o puerpério.

Para uma efetiva assistência de enfermagem à mulher durante o puerpério, de forma a promover sua adaptação às peculiaridades desse período, é primordial uma interação entre ela e o(a) cuidador(a) e que o processo de cuidar seja iniciado ainda durante a gestação e fortalecido no pós-parto. Para o alcance dessa meta, o planejamento do cuidado deve ser estabelecido pelo enfermeiro durante o pré-natal, englobando o atendimento da gestante em suas necessidades físicas, psicológicas e educacionais, devendo o enfermeiro apropriar-se do reconhecimento das informações, crenças e valores familiares positivos e buscar desmitificar o que lhe parecer negativo. ${ }^{5}$

Trabalhando nesses moldes, o enfermeiro, sem dúvidas, conseguirá realizar o dimensionamento da real situação em que esteja trabalhando, de forma a promover o alívio de ansiedades, a superação de dúvidas e de temores, a fim de ampliar a margem de segurança com relação ao parto. É importante que o(a) enfermeiro(a) ocupe esse espaço e desenvolva uma interação efetiva entre a equipe de enfermagem e a clientela.

Em estudo realizado anteriormente, pôde-se perceber que o suporte emocional e informativo proporcionado pela enfermeira à mulher durante o trabalho de parto e o parto reduziu o medo, a ansiedade e o sofrimento, proporcionando a aquisição de autoconfiança, resposta comportamental adaptativa relevante para a evolução do trabalho de parto e para a eclosão de um parto com tranqüilidade. ${ }^{6}$

Entretanto, urge a necessidade de um redimensionamento da assistência de enfermagem à mulher para uma assistência qualificada, motivo pelo qual consideramos este estudo um desafio, mas também uma excelente contribuição para a prática da enfermagem obstétrica, realizado com base em representações da mulher sobre a experiência da maternidade e a aprendizagem do autocuidado no pós-parto.

Para obter essa qualidade, é necessário que, no preparo oferecido à mulher, durante o pré-natal, sejam incluídos cuidados para o puerpério, de tal forma que 
essa mulher vá aos poucos assimilando o cuidado e o autocuidado que ela deverá realizar durante o seu período puerperal.

Neste estudo, trabalhamos com as representações das puérperas sobre os ensinamentos que a mulher no puerpério recebe sobre o autocuidado, que deverá ser realizado por ela durante o pós-parto, e decorrentes da preparação recebida por ela durante a gravidez, de forma a enfrentar o puerpério e a se adaptar a essa fase, enfrentando suas peculiaridades.

Destacamos, pois, como questão norteadora para este estudo, a seguinte: os cuidados e os ensinamentos de enfermagem promovidos à mulher no puerpério garantem a segurança para ela cuidar de si e de seu filho? Acreditando que a Teoria das Representações Sociais ${ }^{7,8}$ poderá, a partir da percepção das puérperas acerca do processo de autocuidar-se, subsidiar a compreensão dessa problemática, podendo, também, caracterizar a assistência de enfermagem durante o ciclo puerperal, apoiamos nela a discussão, esperando poder, assim, oferecer um direcionamento para a prática efetiva de enfermagem, que deve ser desenvolvida nas puérperas.

Objetivamos, então, analisar as representações sociais de puérperas sobre o cuidado de enfermagem e os ensinamentos recebidos no ciclo puerperal sobre o cuidado consigo própria e com seu filho.

\section{METODOLOGIA}

O estudo é de abordagem qualitativa, norteado pelo eixo teórico das Representações Sociais. ${ }^{7-9}$ Visto que a abordagem qualitativa requer aprofundamento das informações emitidas pelos sujeitos participantes, procuramos cultivar um clima de confiança nas participantes visando à obtenção de maior veracidade nas respostas, estimular a participação e promover a interação pesquisadora-pesquisados, aproximando-nos do cenário da pesquisa e dos sujeitos do estudo, antes mesmo de iniciar o processo de obtenção dos dados.

$\mathrm{O}$ estudo foi iniciado em um hospital-maternidade da rede municipal, que presta atendimento de saúde à população, em nível primário e secundário, e integra a Secretaria Executiva Regional VI (SERVI) no Município de Fortaleza - Ceará. Outro cenário eleito para a pesquisa, constituiu-se do domicílio das puérperas, pelo fato de fortalecer a interação iniciada na instituição pesquisada e permitir uma maior liberdade de expressão por parte das entrevistadas.

As participantes do estudo constituíram-se de sete puérperas que vivenciavam pela primeira vez a experiência da maternidade e que se dispuseram a participar do mesmo, concedendo consentimento verbal e escrito, através da assinatura do termo de consentimento livre e esclarecido fornecido pela pesquisadora.

A coleta de dados foi realizada durante o período de março a setembro de 2004, a partir da unidade de alojamento conjunto, onde foram selecionadas as puérperas participantes do estudo. Durante esse contato com as puérperas, a pesquisadora combinou com algumas primíparas visitas domiciliares para fortalecer o processo interativo entre pesquisadora e pesquisadas. As visitas variaram entre uma e duas, com a primeira visita realizada entre o $2^{\circ}$ e o $30^{\circ}$ dia após a alta hospitalar, quando foi realizada uma entrevista semi-estruturada com roteiro abrangendo dados sociodemográficos e questões abertas, direcionadas às representações das mulheres sobre o período puerperal e sobre a preparação que essas mulheres receberam pela equipe de enfermagem para enfrentar o puerpério. Foram propostas as seguintes questões para a entrevista: como você representa o cuidado de enfermagem recebido no puerpério? Quais foram os ensinamentos recebidos durante o puerpério no âmbito hospitalar e domiciliar?

Outra técnica de obtenção dos dados utilizada foi a observação livre com registro em diário de campo, a fim de registrar as expressões corporais, as reações das entrevistadas às perguntas, atitudes e outros aspectos impossíveis de serem referidos verbalmente ou de serem gravados, quando a escuta cuidadosa e reflexiva favorecia a pesquisadora relembrar aspectos subjetivos manifestos pelas entrevistadas no momento das entrevistas. A observação foi realizada, também, em alguns momentos em que o cuidado de enfermagem era dispensado às puérperas na unidade de alojamento conjunto, o que contribuiu para a análise dos depoimentos vinculados à assistência de enfermagem recebida no puerpério.

Os dados obtidos foram organizados a partir do método de análise de conteúdo. ${ }^{10}$ De acordo com a convergência das respostas das puérperas, elegemos as duas seguintes categorias de análise: a) o cuidado recebido na maternidade; b) interação e o cuidado no domicílio.

Os aspectos éticos concernentes à pesquisa com seres humanos, ditados na Resolução 196/96 do Conselho Nacional de Saúde, ${ }^{11}$ foram atendidos, com pesquisa de campo iniciada somente após parecer favorável do Comitê de Ética da Universidade Federal do Ceará. Foi concedido, ainda, às puérperas que aceita- 
ram a participação na pesquisa, termo de consentimento livre e esclarecido.

\section{O CUIDADO RECEBIDO NA MATERNI- DADE}

As puérperas revelaram-se muito decepcionadas com o cuidado recebido, na fase puerperal, enquanto estiveram no centro obstétrico. No alojamento conjunto, enquanto a mãe permanece com o seu bebê por 24 horas, no mínimo, não foi associado pelas puérperas a um ambiente acolhedor, de aprendizagem, de liberdade e de interação interpessoal entre profissional e clientes. Ao contrário, a unidade puerperal foi representada como um lugar de abandono, onde a presença da enfermeira e das auxiliares pouco contribuiu para a adaptação da mulher ao puerpério e onde as solicitações de ajuda pouco eram atendidas, conforme revelação de revolta a seguir: [...] eu me senti muito abandonada, sabe, eu me senti tão abandonada, que eu, vendo as outras, eu era que me levantava pra ajudar as outras, porque não tinha enfermeira nem auxiliar que viesse ajudar. Isso aconteceu comigo e eu não sei se é uma coisa minha mesmo; eu sei que eu peguei o bebê e vi que ele tava dormindo, eu botei no berço, ai eu fiquei um tempo deitada, ai aquele pano lá, aquele forro começou a me incomodar e eu fui pedir pra tomar um banho, porque não me avisaram que en podia tomar banho, ai eu fui perguntar, eu posso tomar banho? Ela disse, pode, ai en pedi outra roupa, outro forro, me deram. Mas outra coisa que eu não gostei foi o jeito que trataram, não que paparicassem, porque eu sei que en não tava em hospital particular, mas eu acho assim, que uma atenção maior, principalmente com quem estava ali pela primeira vez, tinha eu e outra moça que estavam ali pela primeira vez. [...] (Sara).

Diante da fala de Sara, a impressão que fica é a de que não haveria diferença alguma entre a presença física da equipe de enfermagem e a sua ausência na unidade, pois as mesmas estavam presentes no plantão, mas omissas em relação ao cuidado dispensado às puérperas. Essas apoiavam uma às outras para minimizar a sensação de abandono e solidarizavam-se quando surgia alguma solicitação de ajuda, conforme revela Sara na seguinte frase: eu era que me levantava pra ajudar as outras.

O abandono sofrido pela mulher diante da hospitalização diz respeito, especialmente, às dúvidas, inseguranças e obstáculos condizentes com o desempenho do papel materno e da amamentação, sendo este fato comprovado por estudos, que consideram o enfermeiro ausente, enquanto agente facilitador do aleitamento materno às puérperas, e quando salientam que as mulheres atribuem à sensação de abandono durante sua hospitalização, não só na fase puerperal, mas também quando são admitidas no centro obstétrico. ${ }^{12-13}$

Essas insatisfações prevalecem, ainda mais quando as puérperas se referem ao turno da noite, quando o quantitativo de profissionais é percebido como reduzido, o que impede a cobertura e a qualidade do cuidado a ser oferecido ao binômio mãe e filho.

[...] Não vieram ver se eu tava dando de mamar, o bebê passou muito tempo sem mamar, eu tentava e ele não pegava, ele passou muito tempo dormindo. Quando eu comecei a observar os outros bebês mamando, foi que eu perguntei alguma coisa, foi que elas disseram, você tem que estimular, acorde ele e bote pra mamar, só o que diziam [...] chega uma determinada hora da noite que a gente fica só ali dentro e eu vi moça precisando de água, com cólica [...] coisas que eu não senti, tô sentindo agora, então ela tava sem poder se levantar e tava se torcendo em cima da cama, dando de mamar. Ela no auge da cólica, mais o neném, ali no seio dela [...] outras lá, de cesariana, com dificuldades de descer das camas altíssimas, porque não tem aquelas escadinhas que dê pra todas as camas, ai quando precisava, uma pegando da outra [...] (Sara).

Eu gostei das acomodações, só na parte da noite que a gente ficava muito só e se precisasse de alguém era até dificil porque tinha pouca gente (Rute).

Depreende-se, das falas de Sara e de Rute, suas insatisfações com o cuidado de enfermagem, ainda maiores durante o turno da noite, em que a insuficiência de pessoal da enfermagem é ainda mais séria. Entretanto, apesar de, no plantão diurno, a equipe de enfermagem se ampliar, levando-se em consideração que há outros elementos colaboradores do cuidado, devido à inserção dos acadêmicos de enfermagem e dos docentes, assim como do pessoal de nível técnico, auxiliares e técnicos de enfermagem voluntários ou estagiários, existe também uma grande sensação de abandono e de solidão para as puérperas.

Sara relata que presenciou mulheres sentindo dor, usando a expressão se torcendo de dor em cima de uma cama e sem poder se levantar, o que a motivava a ajudar, haja vista que ela se sentia bem e sem intercorrências no período. Enfim, Sara se diz revoltada ao se lembrar das orientações de enfermagem que deixaram de ser realizadas durante sua hospitalização, o que caracterizou como recomendações superficiais e que não contribuíram para que ela amamentasse, pois se restringiram a: você tem que estimular, acorde ele, bote pra mamar, não havendo interesse por parte da equipe para ouvir os motivos pelos quais Sara não amamentava e para estabelecer metas juntamente com ela em favor dessa prática. 
Um ponto convergente com esse resultado supracitado merece destaque em um estudo, no qual os usuários revelaram aspectos negativos que vivenciaram no cotidiano hospitalar e se relacionaram com a equipe de enfermagem assistencial, em que os mesmos presenciaram o sofrimento de outras pessoas no período noturno, conduzindo à insegurança e à sensação de que as pessoas poderiam morrer por falta de assistência. $\mathrm{O}$ conflito relatado entre o usuário e o auxiliar de enfermagem corrobora a idéia de que os valores pessoais levados pelos profissionais para esse encontro poderiam ser revistos a fim de tornar essa relação menos complexa. ${ }^{14}$

Rute salienta que testemunhou atitudes grosseiras por parte da equipe de enfermagem com as puérperas e, com mais evidência, por parte dos auxiliares de enfermagem que não souberam administrar o estresse gerado pela sobrecarga de trabalho.

[...] teve um momento também que eu senti um pouco de estresse por parte dos enfermeiros e auxiliares. Eu acho que foi pelo fato de naquele final de semana nascerem muitas crianças, era muita gente e tava até sem acomodações [...] teve um momento que eu senti um pouco de estresse, de correria dos auxiliares sem poder atender todo mundo e sendo até um pouco grosseiros com os pacientes. A gente via que às vezes eles falavam alto e já tentavam consertar, já se percebe que está se fazendo um trabalbo [...] (Rute).

Eu não tive queixas do atendimento, mas melhorar sempre é bem-vindo. Melhorar na maneira deles (equipe de enfermagem) falar com a gente, que alguns deles eram muito abusados, ainda mais porque quem trabalha em serviço público estressa, mais ai não precisa tratar mal (Ester).

As representações apresentadas nos depoimentos de Rute e de Ester assemelham-se e associam os membros da equipe de enfermagem a grosseiros e abusados, entendendo que momentos de estresse são previsíveis e de certa forma compreensíveis, quando a demanda de pacientes é muito grande, mas não pode comprometer a qualidade da assistência prestada à clientela.

Pelo depoimento de Ester, compreendemos a necessidade de preservar o lado humanístico do cuidar, investindo mais na relação interpessoal dos profissionais de enfermagem. Concordamos com alguns autores, quando integram ao cuidado instrumental de enfermagem o afeto e a atenção, como elementos imprescindíveis ao relacionamento entre profissional e cliente: quando o primeiro se torna disponível, trata, ouve, atende e está ao lado do cliente, por inteiro, e não simplesmente presente. ${ }^{15,16}$
Conforme relatos de Maria e de Sara apresentados abaixo, compreendemos que há necessidade de um redirecionamento da assistência de enfermagem para as primíparas, atentando-se para os elementos subjetivos do cuidado, ressaltados pelos autores já mencionados.

[...] não achei bom não, porque eu só via elas no momento em que iam pegar o bebê pra banhar, depois eu não via mais não... en acho que nesse ponto deveria melhorar... en acho que deveria ser assim, porque no meu caso eu nem falo tanto, porque en tive a experiência de cuidar de meus sobrinhos, mas tem muita mãe ali que é o primeiro filho também, e são muito novas, não têm experiência né, como cuidar da criança, como se pega, como vai colocar no peito pra criança mamar... acho que elas deveriam se aproximar mais das mães de primeiro filho [...] (Maria).

[...] só sei que era uma coisa que devia ser feita ali dentro daquela parte (alojamento conjunto) uma atenção com as mães de primeiro filho, porque en convivi com muitas ali, isso foi a minha noite, aconteceu da moça que se levantou de uma vez com a criança e teve uma tontura e ao mesmo tempo que ela teve uma tontura, a criança sujou, tava sem fralda, porque ela tava se preparando pra ajeitar a criança, ai sujou tudo lá sabe, a auxiliar viu e deu um carão na moça em vez de ajudar primeiro [...] aí, foi que en fui lá, pegar o algodão e se não tivesse algodão tinha que esperar o algodão aparecer e pra elas darem esse algodão primeiro elas davam uma rabissaca [...] elas dão mais importância a um pedaço de papel que tão escrevendo do que a gente que tá precisando delas. Elas passam mais tempo dentro do postinho do que nas enfermarias olhando a gente [...] e de noite só quem recebe a visita das auxiliares é só quem tem que tomar algum remédio prescrito pelo médico; ai é que elas vêm [...] (Sara).

Inferimos, com base nos depoimentos de Maria e de Sara, que a enfermagem precisa repensar sua prática, incorporando atitudes humanísticas, substituindo posturas desumanas e antiéticas, por interações harmoniosas a serem estabelecidas, em particular com a primípara. Essa vivencia uma fase especial de sua existência, que é ao mesmo tempo uma fase repleta de medos e de insegurança, frente ao desconhecido exercício do papel materno.

Vale ressaltar que a enfermeira, ao acompanhar a mulher no processo de nascimento, precisa adquirir, além de competência técnica, a capacidade de estar presente de forma autêntica e procurar compreender a mulher em toda a sua singularidade. Para tanto, a "correria" precisa ser substituída pela capacidade de saber enfrentar situações difíceis com um sorriso e com tranqüilidade. $^{17}$ 
Outras causas da insatisfação das puérperas, no que concerne ao cuidado de enfermagem, é a excessiva valorização do aspecto burocrático, em detrimento do aspecto assistencial, não havendo um equilíbrio entre essas duas faces do cuidado, o que pode se perceber pelas declarações de Sara, ao observar que elas dão mais importância a um pedaço de papel do que a gente que tá precisando delas. Outros depoimentos descritos a seguir reforçam a necessidade de uma maior atenção, no que diz respeito à maneira de algumas profissionais da equipe se comunicarem com as puérperas, não se referindo a toda a equipe de enfermagem do hospital, mas a algumas integrantes, as quais não puderam ser identificadas. Os depoimentos de Judite e de Raquel ilustram bem esse fato: [...] acho que deveria ter mais atenção, assim comigo não, porque têm aquelas que já é mais forçado o parto né [...] um atendimento melhor por parte da equipe todinha, porque, às vezes, as mulheres quando vêm entregar o almoço, as pobes não podiam nem se levantar, se sentar, ai as mulheres diziam umbora, umbora, se sente, se sente, não quer nem saber se a pessoa tá ponteada e se num tá, Ave Maria, não (Raquel).

Eu fui muito bem tratada por algumas pessoas, não foram todas, eu não sei identificar se eram auxiliares ou enfermeiras. Quanto às pessoas que tavam no balcão (Posto de Enfermagem) que eu não sei identificar foram um pouco [...] eu não gosto de ser chamada a atenção na frente dos outros, você quer falar comigo, que chame. Eu cheguei lá e disse que tava precisando tomar banho, ai ela (profissional de enfermagem) disse: e o banheiro não tá lá não, ele saiu do lugar, ai eu disse, não, é porque eu quero pelo menos um absorvente, eu vou tomar banho, eu preciso trocar o absorvente, ai ela me deu. Nenhuma pessoa gosta de ser tratada dessa forma, né, o tom, não precisava daquilo [...] eu fiquei bastante magoada que nem prestei atenção quem era, eu ia lá mais não perguntava mais nada. Outras profissionais chegavam na enfermaria e perguntavam: 0 que você tá precisando? Tem toalha aí? Não, mais eu já vou providenciar (Judite).

Um fato comum, existente entre as puérperas inquiridas sobre o cuidado dispensado às mesmas e às outras mulheres que compartilhavam da primeira experiência de maternidade, foi a falta de diálogo por parte dos profissionais que se incumbiam do cuidado ao binômio mãe e filho e atitudes irônicas e antiéticas, tais como exemplifica a colocação feita pelo profissional, o banheiro não ta lá não, e como outras já destacadas anteriormente.

Raquel estende a falha na comunicação a outros funcionários da instituição, quando se refere à falta de paciência das copeiras, ao fazer exigências às puérperas, que se encontravam impossibilitas de cumprir, em face das suas condições físicas ainda desfavoráveis para a deambulação.

\section{A INTERAÇÃO E O CUIDADO NO DO- MICÍLIO}

A prática educativa se insere no cuidado de enfermagem em todos os contextos de atuação do enfermeiro, uma vez que a relação enfermeira-cliente não se faz possível sem a utilização de um importante instrumento, denominado educação e comunicação.

As correntes e teorias que defendem a educação ampliaram-se nos anos 90 e muitos referenciais surgiram com a intenção de motivar o educador a repensar suas posturas profissionais e sua prática pedagógica junto ao aluno e/ou ao usuário do serviço de saúde, objetivando, também, romper com os modelos de educação verticalizada, na qual o trabalho educativo circula em um único sentido, de emissor-receptor, este último tido como "caixas-vazias", representado pela população usuária dos serviços de saúde que aceita esse conhecimento como pronto e acabado. ${ }^{18}$

A arte de educar o cliente, a família ou a comunidade deve ser compreendida como algo mais do que atividade de passar conteúdos ou proporcionar espaço temporal para a prática de procedimentos aprendidos em laboratórios simulados e fora do contexto social daquele indivíduo. ${ }^{19}$

$\mathrm{Na}$ prática de enfermagem obstétrica, ainda deparamos com atitudes do profissional centradas no modelo de educação tradicional, em que não há espaço para perguntas e para um processo de comunicação efetivo entre profissional e cliente. A dimensão técnica do cuidar assume a prioridade nos atendimentos às gestantes, parturientes e puérperas, deixando uma lacuna nesse processo de cuidar, que faz grande diferença para a mulher, ao término do processo gestacional, quando depara com uma série de dúvidas e dificuldades para desempenhar o papel materno.

Algumas puérperas entrevistadas referiram deficiência de informações sobre o período puerperal e as suas particularidades durante o pré-natal, as quais se estenderam até sua alta hospitalar. Mesmo após dois dias internadas no sistema de alojamento conjunto, as dúvidas e a insegurança referentes à prática da amamentação persistiram, conforme refere Sara: eu acho que em particular a falta de informações me atrapalhou, porque ainda mais que ele nasceu com esse problema, da icterícia né, aí ele tinha que mamar mais do que os outros e eu só fiquei sabendo depois [...] e ele nasceu quatro horas da tarde, eu acho que de manhã é que eu tive assistência pra ele mamar direito. Os dois 
seios feriram e um deles chegou a querer pedrar e uma irmã que tava comigo, ai ela notou logo e sentiu quente, ai disse, Sara, pelo amor de Deus, bote logo alguma coisa aí, usei pomada e sarou... assim, fez. uma grande falta pra mim em particular essas instruções sobre amamentação lá dentro do alojamento, quando eu sai da sala de parto, fez uma falta tremenda (Sara).

Sara refere, nesta fala, a repercussão de forma negativa da falta de informações na instituição hospitalar, quando, em sua fase puerperal, teve que passar por muito sofrimento, para poder conviver harmonicamente com esse período, desconhecido e inesperado por ela. Acrescenta que a assistência centrada na dimensão educativa não aconteceu, mas menciona que percebeu um empenho por parte de uma enfermeira, na manhã do dia seguinte do seu parto, tendo havido uma aproximação e um interesse em ajudar a puérpera a estabelecer uma postura e técnica correta de amamentar, porém, o curto tempo de interação não proporcionou uma adequada assimilação desse conhecimento. $\mathrm{Na}$ sala de parto en tive uma orientação rápida sobre a amamentação. Quando eu tive neném, tava todo mundo ocupada com alguma coisa, porque naquele dia tinha muita mãezinha [...] no segundo dia, uma enfermeira que deu a massagem no meu peito, ela disse: olha mãe, não existe leite fraco não, um tantinho que ele tomar, é importante pro seu filho, mais não entrava na minha cabeça e foi uma coisa tão rápida que eu não peguei (Sara).

No contexto da prática de enfermagem obstétrica, salienta-se que "a educação é um dos principais componentes do cuidado com a gestante, parturiente, puérpera e família, seja no ambulatório, hospital ou domicílio. É a oportunidade para a promoção da saúde e prevenção das doenças. É o suporte para a compreensão do processo de gestação e dos riscos, podendo ser um dos instrumentos de capacitação e de socialização de conhecimentos". 20:104

Observa-se, atualmente, na enfermagem obstétrica um avanço no conhecimento técnico-científico, com a crescente qualificação de enfermeiras obstétricas, que buscam obter um melhor preparo técnico para atender com mais qualidade à gestante, à parturiente e à puérpera. No entanto, a qualidade desse cuidado nem sempre pressupõe comunicação acessível, de forma que haja um entendimento por parte da mulher.

As puérperas participantes do estudo, ao serem indagadas acerca da prática educativa após a alta hospitalar, o domicílio foi definido por todas como um importante cenário para a extensão do cuidado de enfermagem hospitalar, uma vez que elas não se sentiam preparadas e seguras para o desempenho do novo papel.
Considera-se o domicílio da puérpera de extremo valor, porquanto o objetivo primordial da enfermeira é conseguir o bem-estar da puérpera, através do planejamento de cuidados condizentes com os diagnósticos de enfermagem, considerando cada situação em particular, sendo flexível ao plano estabelecido e mantendo-se aberta para discutir as eventuais dúvidas e preocupações vivenciadas ao longo do puerpério ${ }^{21}$.

As puérperas foram unânimes em dizer que não receberam nenhuma visita por parte da Equipe de Saúde da Família, referindo terem sido as visitas realizadas por ocasião da pesquisa, as únicas e de grande importância para elas, conforme foi destacado por Maria, Ester e Sara.

Não tive nenhum contato com a enfermeira no domicílio, a única pessoa que eu tive contato foi contigo mesmo (pesquisadora), mais ninguém [...] a gente passa por muitas coisas e muitas dores e a gente faz. coisas que a gente nem imagina fazer, então, seria bom a gente ter um acompanhamento assim, porque como eu te falei, no outro dia que você passou no quarto, que eu te chamei, agradeci, então, do mesmo jeito que eu te agradeci, eu queria ter o prazer de ver elas também e agradecer por elas ter feito isso por mim, certo que é obrigação delas, mas têm muitas pessoas que não fazem o que elas fizeram né, Graças a Deus eu tive sorte, eu tive muito apoio mesmo, é tanto que eu não me senti só [...] então eu acho importante isso aí, porque na hora a gente quer falar, quer agradecer, mais a gente não se acha com condições, depois que a gente passa por tudo, aí, é que a gente se acha com condições de falar e a gente não vê mais aquelas pessoas, então eu acho importante por esse lado aí [...] (Maria)

$E u$ acho que seria uma ótima que viesse realmente alguém depois que a gente saísse do hospital porque quem tem mãe por perto, a mãe ajuda, mas quem não tem, tem que se virar só e às vezes fica mais difícil [...] seria uma ótima se tivesse uma pessoa pra acompanhar, pelo menos uma visita [...] eu só tenho a parabenizar esse teu projeto, esse trabalho, eu gostei muito e achei bastante interessante porque é o meu suporte, foi o meu suporte e está sendo né, depois do resguardo e é um projeto maravilhoso. Se continuar, só vai fazer coisa boa (Ester).

Até hoje eu tô agradecendo a Deus porque muitas dúvidas eu tô tirando com você. Quem dera que as mães, pelo menos as de primeira viagem, tivessem esse atendimento [...] é até uma segurança que a gente tem, sabe, ter alguém [...]. Ah, se o posto de saúde oferecesse isso pra gente, mesmo que a gente tivesse que se deslocar até lá, mais a gente tinha pra onde correr (Sara).

Sara referiu gratificação com a iniciativa desta pesquisa, uma vez que possibilitou elucidar dúvidas existentes sobre a maternidade, por intermédio da pesquisadora, enfatizando que o posto de saúde deveria 
oferecer visitas domiciliares, para aumentar a segurança e a autoconfiança da mãe, ao enfrentar o puerpério.

A prática educativa possibilitada pelas visitas domiciliares realizadas às puérperas foi associada pelas mesmas a um suporte importante, que deve ser implementado nas instituições de saúde de maneira mais efetiva e que possa ser estendido ao domicílio, havendo necessidade de uma melhor articulação dos serviços de atenção básica com os de atenção secundária. É necessário desfocar a atuação junto à mulher gestante ou puérpera para uma intervenção na particularidade da comunidade da qual ela participa, pois sendo a amamentação uma prática social, esta não é responsabilidade exclusiva de um agente, mas demanda apoio de uma rede social. ${ }^{22}$

A primeira consulta do pós-parto, em geral, ocorre tardiamente, em torno do $42^{\circ}$ ao $45^{\circ}$ dia pós-parto, tempo suficiente para a instalação de complicações obstétricas e/ou intercorrências da lactação, com conseqüente desmame precoce, tendo em vista que somente o processo de internação na unidade de aloja- mento conjunto e a assistência de enfermagem prestada não deixam a mulher segura para a prática da amamentação e para aquisição de conhecimento sobre os cuidados com o recém-nascido. É válido ressaltar que, das consultas puerperais aprazadas, o acesso às consultas é estimado em torno de $20 \%$ a $23 \%$, o que acarreta um maior risco à saúde da mulher e do recém-nascido. $^{23}$

É urgente e necessário repensar iniciativas para preencher ou encurtar esse intervalo da consulta puerperal, que além de expor a mulher e o recém-nascido a complicações e óbitos, representa um período difícil e novo na vida da puérpera, que anseia por um suporte profissional que atenda as suas expectativas, responda as suas dúvidas e lhe transfira autoconfiança indispensável ao desempenho materno.

A seguir, apresentamos um diagrama que reúne as representações sociais do cuidado de enfermagem mais referidas pelas puérperas, estando implícitos os dois processos de formação da teoria de representações sociais, a objetivação e a ancoragem.

\section{REPRESENTAÇÕES SOCIAIS DAS PUÉRPERAS SOBRE O CUIDADO RECEBIDO}

Insatisfação com o cuidado recebido na maternidade

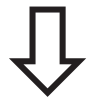

\section{REPRESENTAÇÕES}

Lugar de abandono;

Atitudes grosseiras e antiéticas do profissional;

Aspecto burocrático prevalece sobre o cuidado assistencial;

Equipe de enfermagem pouco presente, pouco comunicativa e pouco atenciosa.
A interação e o cuidado no domicílio

\section{REPRESENTAÇÕES}

Puerpério, período difícil e novo na vida da mulher;

Aumenta a segurança, a autoconfiança da mãe;

Gratificação com a iniciativa da pesquisa;

Suporte importante, deve ser implementado de maneira mais efetiva;

Possibilita elucidar dúvidas sobre a maternidade. 


\section{CONCLUSÃO}

A maioria das puérperas referiu insatisfação com o cuidado dispensado pela equipe de enfermagem durante sua hospitalização e sua permanência no alojamento conjunto, cujas representações destacaram-se por: lugar de abandono, equipe de enfermagem grosseira e antiética, que faz prevalecer o aspecto burocrático na administração do cuidado às pacientes. $\mathrm{E}$ ainda: deficiência de orientações no serviço de saúde, tanto no contexto ambulatorial quanto no hospitalar, fazendo persistir as dúvidas e inseguranças das mulheres inerentes à prática da amamentação; ausência de uma prática extensiva do cuidado hospitalar para o domicílio, circunstância essa que gera descontentamentos entre as puérperas, e influência na insegurança em face do exercício do papel materno.

Consideramos que o cuidado de enfermagem dispensado à mulher durante o ciclo gravídicopuerperal não garante a autoconfiança necessária para o desempenho dos cuidados consigo mesma e dos cuidados com o neonato, no período puerperal. É imprescindível que a enfermagem ocupe o seu espaço de atuação nas consultas de pré-natal, procurando estabelecer uma interação efetiva com a mulher, enquanto ser gestante que experiencia uma série de acontecimentos novos. Especialmente, no centro obstétrico e no pós-parto, quando o seu papel, enquanto educadora em saúde, se potencializa mais ainda, haja vista uma maior necessidade de aproximação, de diálogo e de suporte com as puérperas, em razão das dificuldades com que elas se deparam.

Apesar da insatisfação das puérperas com o cuidado institucional, percebemos que as mesmas expressaram satisfação e gratidão pelos ensinamentos passados no âmbito domiciliar na ocasião da pesquisa, que foi considerada um suporte de grande importância.

\section{REFERÊNCIAS}

1 Zampieri MFM. Enfocando a concepção e a gestação em uma perspectiva histórica e social. Nursing: rev. técn. enferm. 2001 Jun; 4 (37): 15-9.

2 Largura M. A assistência ao parto no Brasil: aspectos espirituais, psicológicos, biológicos e sociais - uma análise crítica - por um parto mais humano e solidário. 2a ed. São Paulo: Savier; 2000.

3 Radunz V. Cuidando e se cuidando: fortalecendo o self do cliente oncológico e o self da enfermeira. Goiânia: AB; 1999.
4 Rodrigues DP, Montesuma FG. Contribuição social dos formandos na assistência de enfermagem à mulher no pré-parto, parto e puerpério. Enferm. Atual. 2003 JanFev; 3 (13): 32-6.

5 Nascimento MGP, Santos OMB, Souza ML. Vivenciando o processo de nascimento. Texto Contexto Enferm. 1997 Jan-Abr; 6 (1): 157-67.

6 Rodrigues DP. Assistência de enfermagem no pré, trans e pós-parto: repercussão no processo adaptativo [monografia]. Fortaleza (CE): UECE/Curso de Pósgraduação em Enfermagem Obstétrica; 2002.

7 Moscovici S. A representação social da psicanálise. 2a ed. Rio de Janeiro: Zahar editores; 1978.

8 Moscovici S. Representações sociais: investigações em psicologia social. Petrópolis (RJ): Vozes; 2003.

9 Jodelet D. As representações sociais. Rio de Janeiro: EdUERJ; 2001.

10 Bardin L. Análise de conteúdo. Lisboa: Edições 70 Persona; 1977.

11 Ministério da Saúde (BR), Conselho Nacional de Saúde, Comitê Nacional de Ética em Pesquisa em Seres Humanos. Resolução No 196, de 10 de outubro de 1996: diretrizes de normas regulamentadoras de pesquisa envolvendo seres humanos. Brasília (BR): O Conselho; 1996.

12 Araújo LDS. Querer/poder amamentar: uma questão de representação? [dissertação]. Florianópolis (SC): UFSC/Programa de Pós-Graduação em Enfermagem; 1991.

13 Soares AVNS, Silva IA. Representações de puérperas sobre o sistema alojamento conjunto: do abandono ao acolhimento. Rev. Esc. Enferm USP. 2003 Abr-Jun; 37 (2): $72-80$.

14 Silva AGI. Satisfação do usuário: desvendando as representações sociais sobre a qualidade da assistência. Esc. Anna Nery: rev. enferm. 2002 Dez; 6 (3): 411-23.

15 Merighi MAB. Reflexões sobre a qualidade da assistência de enfermagem à mulher no período gravídico-puerperal. Rev. Enferm. UERJ. 1998 Jun; 6 (1): 253-58.

16 Silva AL. Cuidado como momento de encontro e troca. In: Anais do 50o Congresso Brasileiro de Enfermagem; 1999 Set 20-25; Salvador, Brasil. Salvador: ABEn - Seção BA; 1999. p.74-9.

17 Pinto CMS, Rocha EA, Silva MJP. O toque como elemento de comunicação parturiente/enfermeiro obstetra durante a assistência no pré-parto. Nursing: revista técnica de enferm. 2002 Abr; 5 (47): 31-4. 
18 Cyrino AP, Cyrino EG, Ribeiro A. A comunicação: estratégia para integrar parceiros e fortalecer a cidadania. In: Almeida M, Feuerwerker L, Llanos M, organizadores. Educação dos profissionais de saúde na América Latina: teoria e prática de um movimento de mudança. São Paulo/Buenos Aires/Londrina: Hucitec/Lugar Editorial/Ed. UEL; 1999. p.145-9.

19 Varela ZMV. Habilidades femininas no agir didático. In: Silva RM, Barroso MGT, Varela ZMV. Ensino na Universidade: integrando graduação e pós-graduação. Fortaleza: Pós-Graduação/DENF/UFC/FFOE; 2000. p.17-5.

20 Zampieri MFM. O processo educativo: interpretando o som da humanização. In: Oliveira M, Zampieri MFM, Bruggemann OM. A melodia da humanização: reflexões sobre o cuidado no processo de nascimento. Florianópolis: Cidade Futura; 2001. p.101-7.
21 Martínez MEM. Visita a domicilio a la mujer puérpera. In: Martín L. Atención domiciliaria: diagnosticos de enfermería. Madrid: Interamericana/McGRAW-HILL; 1994. p.159-229.

22 Fracolli LA, Maeda, ST, Brites, PR, Sepúlveda, SCF, Campos, CMS, Zoboli, ELCP. A visita domiciliária sob o enfoque do acolhimento e sua interface com a abordagem do desmame precoce no programa de saúde da família: um relato de experiência. Rev. Eletrônica Enferm. 2003; 5 (2): 78-82.

23 Silveira DMI. Mortalidade materna: realidade que se faz conhecer lentamente [dissertação]. Fortaleza (CE): Mestrado em Saúde Pública/Departamento de Saúde Comunitária/UFC; 2002. 